\title{
Father-Inclusive Perinatal Parent Education Programs: A Systematic Review
}

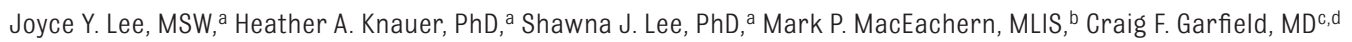

CONTEXT: Fathers contribute to their children's health starting at the beginning of life. Few parent education programs include fathers. Among those that do, there is little effort to report program effects on father outcomes.

OBJECTIVE: In this systematic review, we examined father-inclusive perinatal parent education programs in the United States as they relate to a range of father outcomes.

DATA SOURCES: The databases searched were PubMed, Cumulative Index to Nursing and Allied Health Literature, Embase, Ovid Medline, Cochrane Central Register of Controlled Trials, and PsycINFO.

Study SElection: Studies were included if they included an evaluation of a parent education program and a report of father outcomes measured within 1 year of the child's birth and were conducted within the United States.

DATA EXTRACTION: Of 1353 total articles, 21 met study criteria.

RESULTS: The overall state of the father-inclusive perinatal parent education program literature was poor, with few interventions available to fathers. Available programs were associated with increased father involvement, coparenting relationship, partner relationship quality, father's mental health, and father's supportive behaviors. Program effects on fatherinfant interaction, parenting knowledge, and attitudes and parenting self-efficacy were inconclusive. Three programs emerged as best evidence-based interventions.

LIмıтAтIONS: Risk of bias was high for many studies. Outcome variability, small sample size, and publication bias contributed to the weak evidence base.

conclusions: There is a need for more evidence-based interventions to support fathers.

Clinicians play a key role in engaging fathers in early parent education programs and health care settings. PROSPERO registration number: CRD42017050099.

${ }^{a}$ School of Social Work, University of Michigan, Ann Arbor, Michigan; ${ }^{b}$ Taubman Health Sciences Library, University of Michigan, Ann Arbor, Michigan; ${ }^{c}$ Department of Pediatrics, Feinberg School of Medicine, Northwestern University, Evanston, Illinois; and d'Division of Hospital Based Medicine, Lurie Children's Hospital of Chicago, Chicago, Illinois

Ms Lee conceptualized and designed the study, processed the data, developed the data abstraction and risk of bias instruments, conducted analyses, and drafted the initial manuscript; Dr Knauer processed the data, developed the data abstract and risk of bias instruments, conducted analyses, and drafted portions of the manuscript; Dr Lee conceptualized and designed the study and drafted portions of the manuscript; Mr MacEachern designed the data collection instruments, collected data, conducted analyses, and drafted a portion of the manuscript; Dr Garfield provided input on study conceptualization and design and drafted portions of the manuscript; and all authors reviewed and revised the manuscript and approved the final manuscript as submitted and agree to be accountable for all aspects of the work.

DOI: https://doi.org/10.1542/peds.2018-0437

To cite: Lee JY, Knauer HA, Lee SJ, et al. Father-Inclusive Perinatal Parent Education Programs: A Systematic Review. Pediatrics. 2018;142(1):e20180437 
Father involvement with children has increased in recent decades. ${ }^{1}$ Research has demonstrated the positive contributions fathers make to their children's health and well-being. ${ }^{2-6}$ For instance, father involvement has been linked to decreased risk of prematurity and infant mortality. ${ }^{2,3}$ It has also been associated with the father's parenting confidence, ${ }^{7}$ positive father-child interactions, ${ }^{8,9}$ future father involvement, ${ }^{10}$ and healthier coparenting relationships. ${ }^{11}$ Father involvement benefits fathers themselves; men who are involved with their children report greater physical and mental health. ${ }^{12,13}$

Despite the accumulating evidence for the benefits of father involvement, few early parent education programs have focused on including fathers. The vast majority of existing parent education programs target mothers. ${ }^{14-18}$ This disparity in service likely hinders men's engagement in important pregnancyand childbirth-related decisionmaking processes. It is also important to involve fathers in their children's lives as early as possible because this may serve to reduce the risk of child maltreatment. ${ }^{19-21}$ Among programs that do include fathers, relatively few examine whether program effects are associated with father outcomes separate from that of mother or couple. ${ }^{15}$ This is because mother and father data in analyses have been aggregated in studies. ${ }^{15}$

Previous systematic reviews of father-inclusive parent education programs have been limited by having either a narrow scope (ie, including randomized controlled trials [RCTs] only) or broad scope (ie, looking at child outcomes spanning from infancy to adolescence, including both international and US studies). ${ }^{15,22-25}$ Given the unique characteristics of fathering in the United States, where rates of unmarried childbearing $(40 \%)^{26}$ and nonresidential fathering (16\%)

\begin{tabular}{|c|l|}
\hline Search Number & \multicolumn{1}{c|}{ Search Combination } \\
\hline 1 & (MH "Fathers+") AND (MH "Childbirth Education") \\
\hline 2 & $\begin{array}{l}\text { TI (("ante-natal" OR antenatal OR childbirth OR "peri-natal" OR perinatal } \\
\text { OR "pre-natal" OR prenatal) AND (class* OR "co-parent" OR "co-parenting" } \\
\text { OR coparent* OR course* OR educat* OR interaction* OR intervention* OR } \\
\text { lecture* OR program* OR series OR session* OR talk OR talks OR therap* } \\
\text { OR train*) AND (couple OR couples OR dad OR dads OR father* OR male } \\
\text { OR males OR men OR partner* OR patern* OR parent*))) }\end{array}$ \\
\hline 3 & $\begin{array}{l}\text { AB (("ante-natal" OR antenatal OR childbirth OR "peri-natal" OR perinatal } \\
\text { OR "pre-natal" OR prenatal) N3 (class* OR "co-parent" OR "co-parenting" } \\
\text { OR coparent* OR course* OR educat* OR interaction* OR intervention* OR } \\
\text { lecture* OR program* OR series OR session* OR talk OR talks OR therap* } \\
\text { OR train*) N10 (couples OR dad OR dads OR father* OR male OR males OR } \\
\text { men OR partner* OR patern*))) }\end{array}$ \\
\hline 4 & \begin{tabular}{l}
1 OR 2 OR 3 \\
\hline
\end{tabular} \\
\hline
\end{tabular}

FIGURE 1

A CINAHL adaptation of the search template as an example of the search strategy.

are high, ${ }^{27}$ a review that is focused on US-based interventions is warranted. Hence, our aim in this systematic review was to examine literature on US-based fatherinclusive parent education programs across the perinatal period. We used the Preferred Reporting Items for Systematic Reviews and MetaAnalyses (PRISMA) approach ${ }^{28,29}$ and included a broad range of father outcomes and research designs to ensure comprehensiveness.

\section{METHODS}

\section{Data Sources}

A computer-based search was conducted in 6 electronic databases, including PubMed, the Cumulative Index to Nursing and Allied Health Literature (CINAHL), Embase, Ovid Medline, Cochrane Central Register of Controlled Trials, and PsycINFO on July 28, 2017.

Publication date for included studies was not restricted. Because the United States context in which fathering occurs is diverse, "father" was defined broadly to include biological, residential, nonresidential, adolescent fathers, father figures, and father surrogates. Perinatal was defined as a period spanning from pregnancy through the first year of the child's life.

We created a general search template using keywords for father involvement in perinatal parenting programs that could be applied to all 6 databases with minimal tailoring (see Fig 1 for an example of a CINAHL adaptation) (Supplemental Information). The computer-based search yielded 1353 unique results that were exported to an EndNote $\times 6$ library. ${ }^{30}$ This study was preregistered at PROSPERO: www. crd.york.ac.uk/PROSPERO/display_ record.php?ID=CRD42017050099.

\section{Inclusion and Exclusion Criteria}

To capture the widest breadth, studies were included in this systematic review on the basis of the following criteria: (1) the study was conducted by using experimental (ie, RCT), quasi-experimental (ie, no control group or no pretest), and nonexperimental (eg, qualitative) methods to evaluate perinatal parent education programs; (2) the study included or targeted fathers; (3) a US sample was used in the study; (4) the methods of the study were implemented in various settings (eg, hospital, online); (5) the researchers of the study measured and reported on father outcomes (for details, see 
next section); and (6) the researchers of the study assessed outcomes within 1 year of the child's birth (but could have subsequent follow-up assessments). Studies were included regardless of program effectiveness but were excluded if the researchers only reported aggregated mother and father outcomes or if the studies were not peer-reviewed (eg, dissertations and theses). Detailed inclusion and exclusion criteria can be found in the study's PROSPERO preregistration. By using these criteria, study titles, abstracts, and full-texts were reviewed. In Fig 2, a PRISMA flowchart of this selection process is provided.

\section{Data Abstraction}

The following information was abstracted from each study: author, publication year, study aim, study design, name of the program, population, father outcomes, and results. Abstracted father outcomes included: (1) father-infant interaction; (2) father involvement;

(3) father's parenting knowledge;

(4) father's attitude and parenting self-efficacy; and (5) father's coparenting relationship with the mother. Father's mental health was abstracted as a secondary thematic category, along with "other" father-related outcomes, including partner relationship quality, father's supportive behaviors, and father's evaluation of the intervention.

\section{Data Synthesis}

We used a narrative approach, which is a preferred method when empirical approaches and variables are highly varied across studies, for example, in terms of population, interventions, outcomes, and measurement of outcomes. This approach relies on the use of words and texts to summarize and explain study findings. ${ }^{31}$ We examined aspects of study designs and intervention characteristics as reasons for potential differences in directions
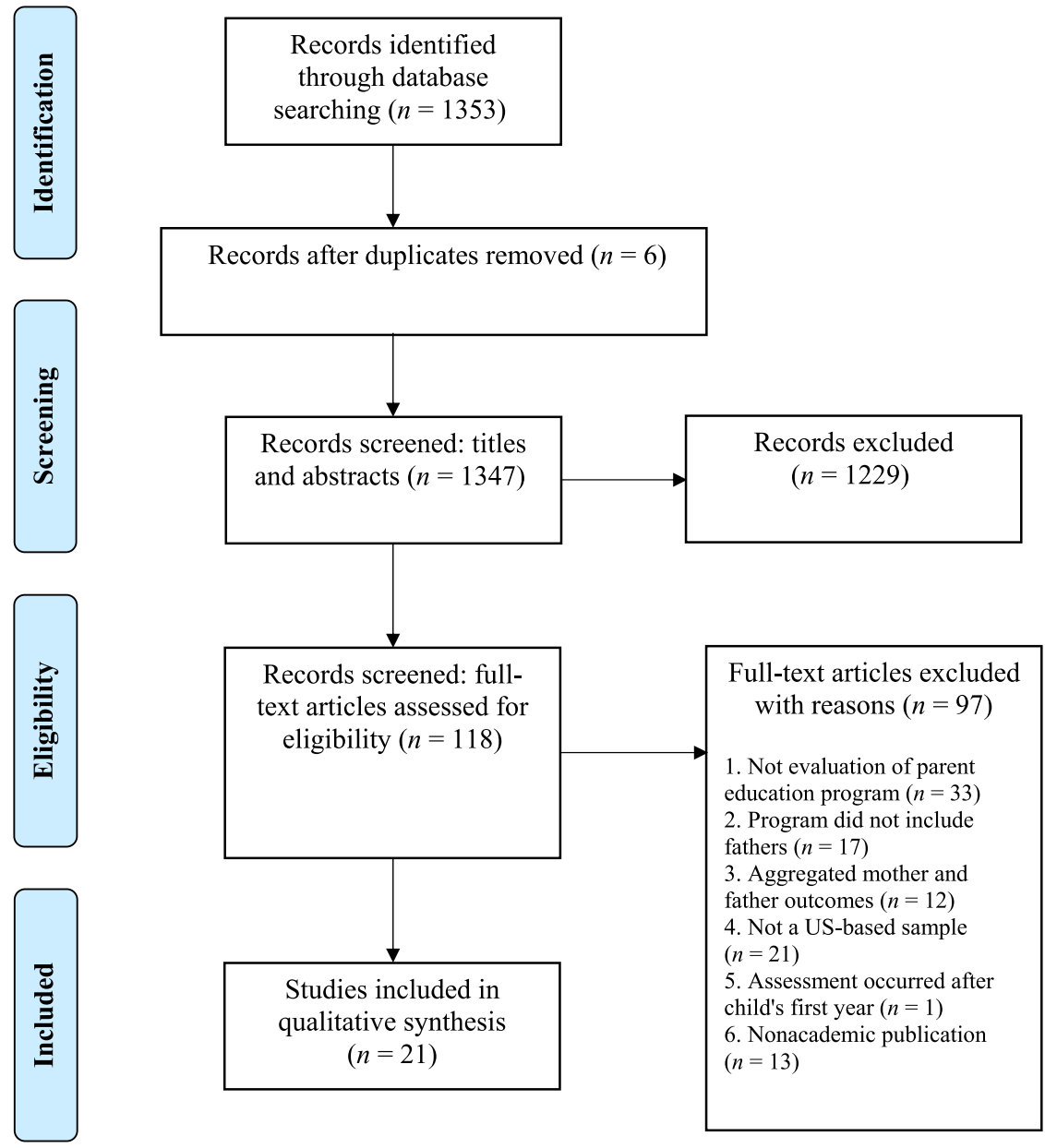

FIGURE 2

A PRISMA flowchart of the study selection process.

and effects across programs..$^{31,32} \mathrm{We}$ used father outcomes as classification schemes for synthesizing data. We also organized the narrative by study design and risk of bias (RoB) assessment to weigh the evidence according to methodological strengths and weaknesses. ${ }^{32}$

\section{Assessment of RoB}

To assess RoB in each study, we used an adapted version of the risk of bias assessment tool for nonrandomized studies (RoBANSs) ${ }^{33}$ rather than the Cochrane Risk of Bias Tool $^{34}$ because of the small number of RCTs and greater flexibility of the RoBANSs in assessing studies with various research designs. We assessed RoB for the following bias categories: participant selection, detection, attrition, and reporting. We assigned an RoB rating for each category as "low," "high," or "unclear." A value of 1 was assigned to low-risk responses and a value of 0 to highrisk and unclear responses. Each study received a total value between 0 and 4 . Studies receiving a score of 2 or less were deemed to be highrisk. The adapted RoBANSs, along with details of each bias category, is included in the study's PROSPERO preregistration.

\section{RESULTS}

\section{Description of Studies}

Twenty-one of 1353 articles met study criteria. Of these, 16 studies were quantitative (7 RCTs, 1 quasiRCT, 7 quasi-experimental, and 1 
nonexperimental) and 5 studies were qualitative (4 mixed methods and 1 phenomenological) (Table 1). In the 21 studies, 19 different fatherinclusive perinatal interventions were evaluated, of which 11 were focused on general education of childbirth and infant care and development, ${ }^{35-46} 4$ were focused on partner relationship and/or coparenting skills, ${ }^{4-51}$ and 4 were clinical- or case management-based interventions (Table 2). ${ }^{52-55}$ In 8 programs, middle-class, majority white parents were primarily targeted. ${ }^{38,40-44,47,48,51}$ In 4 of the programs, unmarried couples were included. ${ }^{35-37,49}$ Four programs were designed for adolescent parents, all of whom were ethnic and racial minorities. ${ }^{39,50,54,55}$ In 8 programs, first-time parents were primarily targeted. ${ }^{35-37,43,47-49,51,52}$ For further details see Table 3 .

Study sample sizes were small, and they ranged between 14 and 173 participants. Most studies included examination of a father-inclusive perinatal parent education program at a single time point. Only 1 study contained an examination of longterm outcomes. ${ }^{48}$ In the majority of the studies, researchers implemented programs in hospital settings, with outcomes based on parents' selfreports. Some researchers delivered the intervention at the group level, ${ }^{35-40,48,55}$ couple level, ${ }^{43,49,52}$ or individual level. ${ }^{10,42,45,46}$ Studies also differed in whether researchers used a manualized curriculum, who delivered the sessions (eg, nurse versus social worker), when the sessions were delivered (eg, before birth versus after birth), and mode of intervention delivery (eg, in-person versus mobile application) (for details see Table 2). Of the 21 studies, only 4 were categorized as low RoB (ie, scoring 3 or higher) and 17 high RoB (ie, scoring 2 or less) as shown in Table 4. Most of the high-risk studies were given that categorization because of the use of convenience

TABLE 1 Research Designs of Included Studies $(N=21)$

\begin{tabular}{lcc}
\hline Research Design & \multicolumn{2}{c}{ Distribution of Studies } \\
\cline { 2 - 3 } & Frequency, $n$ (\%) & Reference No. \\
\hline Quantitative studies & $16(76.2)$ & $34 \cdot 35 \cdot 38 \cdot 46 \cdot 47 \cdot 51 \cdot 52$ \\
RCT & $7(33.3)$ & 49 \\
Quasi-randomized & $1(4.8)$ & $36 \cdot 37 \cdot 54$ \\
Quasi-experimental & $7(33.3)$ & $39 \cdot 40 \cdot 48 \cdot 53$ \\
Pretest-posttest control group & $3(14.3)$ & 41 \\
No pretest or no control group & $4(19.0)$ & $42-45$ \\
Nonexperimental & $1(4.8)$ & 50 \\
Qualitative studies & $5(23.8)$ & \\
Mixed methods & $4(19.0)$ & $1(4.8)$ \\
Phenomenological & & \\
\hline
\end{tabular}

samples, lack of blinding, and income outcome data. The following section provides a narrative synthesis of study outcomes, with more consideration given to studies with low RoB than those with high RoB.

\section{Narrative Synthesis by Father Outcomes}

\section{Father-Infant Relationship}

In 6 quantitative studies (4 RCTs, 1 quasi-experimental, and 1 nonexperimental), researchers examined father-child interaction outcomes. ${ }^{35-37,42,47,52}$ The results of an RCT of a coparenting relationship program $^{47}$ revealed that intervention group fathers demonstrated fewer dysfunctional parent-child interactions (effect size $d=0.70$ ) compared with control group fathers at 6 months postpartum. The results of an RCT of a general education program ${ }^{35,36}$ revealed significantly improved sensitivity during fatherinfant feeding interactions before hospital discharge but not at the 1-month follow-up. The results of a quasi-experimental study of a second general education program ${ }^{37}$ revealed significantly more socioemotional growth fostering by fathers and mutual socioemotional father-child interactions with children ages 6 to 24 months. The results of a nonexperimental study of a third general educational program $^{42}$ revealed a significant link between full program participation and mothers' reports of father-infant relationship. Finally, the results of an RCT of a clinical intervention in which fathers observed a neonatal assessment ${ }^{52}$ revealed improvement in the quality of father-infant interactions at 2 months postpartum. Although all of the above revealed significant positive program effects on some aspect of father-infant interaction, ${ }^{35-37,42,52}$ all but the first $\mathrm{RCT}^{47}$ were at high RoB.

\section{Father Involvement}

Researchers for 4 quantitative studies (2 RCTs, 1 quasi-RCT, and 1 quasi-experimental) examined father involvement outcomes. ${ }^{48,50,52,54}$ The results of an RCT of a coparenting program $^{48}$ revealed significantly more positive parenting $(d=0.45$; eg, support for child exploration) and less negative parenting $(d=$ 0.60 ; eg, irritability) by the father when the child was 1 year old. The results of a quasi-randomized study of another coparenting program ${ }^{50}$ revealed no effects at posttest (during pregnancy) but did reveal a significant improvement in father's engagement in caregiving activities (eg, feeding the infant, changing diapers) by both father's and mother's reports (effect sizes $\eta_{p}^{2}=$ 0.07 and $\eta_{p}^{2}=0.08$, respectively) at 3 months postpartum. Both of these studies were rated to have low RoB. The results of a quasi-experimental study of a case management program for adolescent fathers ${ }^{54}$ revealed that fathers in the intervention group had greater attendance of prenatal health visits, fatherhood 
TABLE 2 Types of Father-Inclusive Perinatal Parent Education Programs $(N=19)$

\begin{tabular}{|c|c|c|}
\hline Author, y & Program Name & Program Description and Details \\
\hline \multicolumn{3}{|l|}{$\begin{array}{l}\text { General education } \\
\text { programs of } \\
\text { childbirth, } \\
\text { infant care, and } \\
\text { development }\end{array}$} \\
\hline Bryan, 372000 & $\begin{array}{l}\text { Growing as a Couple and } \\
\text { Family }\end{array}$ & $\begin{array}{l}\text { The intervention delivered } 3 \text { classes (total } 2 \mathrm{~h} \text { ) of parent-child interaction content in the areas of } \\
\text { parental roles, infant communication abilities, and patterns of development across the first } 3 \text { mo of } \\
\text { the infant's life. Use of manualized curriculum was unclear. Intervention was delivered before birth. } \\
\text { Mode of delivery included media and potentially in-person lessons. }\end{array}$ \\
\hline Diemer,38 1997 & $\mathrm{~N} / \mathrm{A}$ & $\begin{array}{l}\text { The intervention delivered father-focused perinatal discussion classes that included content regarding } \\
\text { pregnancy, childbirth, parenting, social network support, and coping skills. The intervention was } \\
\text { an 8-wk program and used both a standard curriculum by childbirth educators and a curriculum } \\
\text { developed by the researchers. Veteran childbirth teachers taught the classes in person during } \\
\text { pregnancy. }\end{array}$ \\
\hline $\begin{array}{l}\text { Fawcett and } \\
\text { Burritt, }^{43} 1985\end{array}$ & $\mathrm{~N} / \mathrm{A}$ & $\begin{array}{l}\text { The intervention was an antenatal educational program. Mode of delivery involved a pamphlet with } \\
\text { cesarean birth information and a follow-up home visit or telephone call to review the pamphlet } \\
\text { content. The intervention did not use a manualized curriculum. It was unclear who delivered the } \\
\text { intervention. It seems as if intervention occurred during pregnancy. }\end{array}$ \\
\hline $\begin{array}{l}\text { Fawcett and } \\
\qquad \text { Henklin, }{ }^{44} 1987\end{array}$ & $\mathrm{~N} / \mathrm{A}$ & $\begin{array}{l}\text { The intervention involved the same pamphlet as above, as well as focused discussions about caesarian } \\
\text { birth instead of home visit or telephone call. Mode of delivery included a pamphlet and in-person } \\
\text { sessions. There was no manualized curriculum. Discussions were delivered by a childbirth educator } \\
\text { during pregnancy. }\end{array}$ \\
\hline $\begin{array}{l}\text { Hart and Foster, }{ }^{40} \\
1997\end{array}$ & $\mathrm{~N} / \mathrm{A}$ & $\begin{array}{l}\text { The intervention delivered childbirth education classes that included sessions on labor, pain } \\
\text { management, unexpected events, relaxation, vaginal or cesarean birth, and rehearsing labor day. } \\
\text { Use of manualized curriculum was unclear. It was also unclear who delivered the intervention. It } \\
\text { seems to have occurred during pregnancy. Mode of delivery seems to have included both video and } \\
\text { in-person sessions. }\end{array}$ \\
\hline Mackert et al, ${ }^{45} 2015$ & My Pregnancy Today & $\begin{array}{l}\text { The intervention was an e-health application that included a slideshow that detailed fetal development } \\
\text { wk-by-wk. A total of 5-7 min was allotted for navigating and browsing the application content on a } \\
\text { tablet computer. The e-health application was developed by BabyCenter, LLC. It was unclear when the } \\
\text { intervention was delivered. Mode of delivery included mobile device. }\end{array}$ \\
\hline Mackert et al, ${ }^{46} 2017$ & $\mathrm{~N} / \mathrm{A}$ & $\begin{array}{l}\text { The intervention was an e-health application that included a slideshow that detailed fetal development } \\
\text { wk-by-wk. A total of 5-7 min was allotted for navigating and browsing the application content on a } \\
\text { tablet computer. The e-health application was developed by the researchers. It was unclear when the } \\
\text { intervention was delivered. Mode of delivery included mobile device. }\end{array}$ \\
\hline $\begin{array}{l}\text { Pfannenstiel and } \\
\text { Honig, } 35,36 \text { 1991, } \\
1995\end{array}$ & $\begin{array}{l}\text { Information and } \\
\text { Insights About Infants } \\
\text { Intervention }\end{array}$ & $\begin{array}{l}\text { The intervention involved } 2 \text { 1.5-h in-person sessions regarding fetal capacity and functioning, } \\
\text { pregnancy, father self-image, attitude toward infant, infant capacity and functioning, responsive } \\
\text { parent-infant interactions, and skills and activities in caring for an infant. A booklet summarized } \\
\text { content, and a life-size doll was used to model nurturing and caregiving behaviors. The intervention } \\
\text { was delivered between } 2 \text { mo of pregnancy and birth by an "intervenor." }\end{array}$ \\
\hline $\begin{array}{l}\text { Smith and Smith, }{ }^{41} \\
1978\end{array}$ & Parent Education Project & $\begin{array}{l}\text { The intervention involved } 9 \text { in-person prenatal and postpartum group classes to educate parents about } \\
\text { pregnancy, child birth, infant care, parenting, and child development. The intervention employed a } \\
\text { teaching guide to facilitate discussion. The intervention was delivered by an "instructor" and lay } \\
\text { volunteers. Four classes were delivered before birth and } 5 \text { classes were delivered after birth. }\end{array}$ \\
\hline $\begin{array}{c}\text { Van de Carr and } \\
\text { Lehrer, }^{42} 1986\end{array}$ & Prenatal University & $\begin{array}{l}\text { The intervention involved an instructional manual distributed to expectant parents, a video shown in the } \\
\text { physician's office, and a question and answer period with the physician. The intervention materials } \\
\text { included information to enhance fetal development, early communication, brain growth, and health } \\
\text { practices during pregnancy. Two physicians seemed to have delivered the intervention during } \\
\text { pregnancy. Mode of delivery included videos, audios, and in-person sessions. }\end{array}$ \\
\hline Westney et al, ${ }^{39} 1988$ & $\mathrm{~N} / \mathrm{A}$ & $\begin{array}{l}\text { The intervention delivered } 4 \text { 2-h in-person prenatal classes that addressed sexuality, pregnancy } \\
\text { and prenatal care, labor and delivery, and infant and child care. The classes employed lectures, } \\
\text { audiovisual aids, and discussions. Use of manualized curriculum was unclear. The intervention was } \\
\text { delivered during pregnancy by a registered nurse. Mode of delivery included video, audio, and in- } \\
\text { person sessions. }\end{array}$ \\
\hline \multicolumn{3}{|l|}{$\begin{array}{l}\text { Relationship or } \\
\text { coparenting } \\
\text { programs }\end{array}$} \\
\hline Fagan, ${ }^{50} 2008$ & $\begin{array}{l}\text { Minnesota Early Learning } \\
\text { Design for Young Dads }\end{array}$ & $\begin{array}{l}\text { The intervention involved } 5 \text { 1.5-h in-person sessions of a coparenting curriculum to educate young } \\
\text { fathers about responsibilities for parenthood, communication with the mother, benefits to infants } \\
\text { when parents support each other, and development of coparenting solidarity. A manualized } \\
\text { curriculum was used. The intervention was delivered prenatally by experienced social workers and } \\
\text { peers (ie, male African American parents). }\end{array}$ \\
\hline
\end{tabular}


TABLE 2 Continued

\begin{tabular}{|c|c|c|}
\hline Author, y & Program Name & Program Description and Details \\
\hline $\begin{array}{l}\text { Feinberg and Kan, }{ }^{47} \\
\text { 2008; Feinberg } \\
\text { et al, }{ }^{48} 2009\end{array}$ & Family Foundations & $\begin{array}{l}\text { The intervention involved } 8 \text { psychoeducational group classes. The intervention was focused on emotion } \\
\text { management, conflict management, problem solving, communication, and mutual support strategies. } \\
\text { A manualized curriculum was used. Four sessions were delivered prenatally and } 4 \text { postnatally. The } \\
\text { intervention was delivered by a male-female team. Mode of delivery included didactic presentations, } \\
\text { exercises, videos, and group discussion. }\end{array}$ \\
\hline $\begin{array}{l}\text { Gambrel and } \\
\text { Piercy, },^{51} 2015\end{array}$ & $\begin{array}{l}\text { Mindful Transition to } \\
\text { Parenthood Program }\end{array}$ & $\begin{array}{l}\text { The intervention delivered a 4-wk group-based program that used mindfulness practices (eg, body } \\
\text { scan, mindfulness of breath, open awareness) and activities (eg, communication and perspective- } \\
\text { taking exercise) to develop interpersonal attunement. Each session was } 2 \mathrm{~h} \text { long and held once a } \\
\text { wk. Use of a manualized curriculum was unclear. The intervention was delivered by Gambrel }{ }^{51} \text { who } \\
\text { has experience working as a therapist for } 15 \mathrm{y} \text {. It was unclear exactly when the intervention was } \\
\text { delivered, although it seems as if it occurred during pregnancy. Mode of delivery included in-person } \\
\text { sessions. }\end{array}$ \\
\hline $\begin{array}{l}\text { Salman-Engin } \\
\text { et al, }{ }^{49} 2017\end{array}$ & $\begin{array}{l}\text { Figuring It Out for the } \\
\text { Child }\end{array}$ & $\begin{array}{l}\text { The intervention involved } 6 \text { sessions of a dyadic coparenting curriculum, and intervention content } \\
\text { included consciousness raising, skill building, and enactment of skills. A booster session was } \\
\text { delivered } 1 \text { mo postpartum. A manualized curriculum was used. The intervention was delivered } \\
\text { prenatally by } 3 \text { African American male mentors who were affiliated with county fatherhood programs } \\
\text { and } 4 \text { African American female mentors who were experienced home visitors or health educators. } \\
\text { All mentors had experience working with young African American men or women but had little to no } \\
\text { formal couple counseling experiences. Mode of delivery involved in-person sessions. }\end{array}$ \\
\hline \multicolumn{3}{|l|}{$\begin{array}{l}\text { Clinical or case } \\
\text { management } \\
\text { programs }\end{array}$} \\
\hline Barth et al, ${ }^{54} 1988$ & $\begin{array}{l}\text { Teenage Pregnancy and } \\
\text { Parenting Project }\end{array}$ & $\begin{array}{l}\text { The intervention involved in-person sessions with counselors to manage clients across programs } \\
\text { and systems. The intervention provided one-to-one counseling, brokering services, and a weekly } \\
\text { fatherhood group. A manualized curriculum was not used. It was unclear when the intervention } \\
\text { was delivered, although seemingly it was delivered postpartum. The intervention was delivered by } \\
\text { counselors. }\end{array}$ \\
\hline Beal, $^{52} 1989$ & $\begin{array}{r}\text { Neonatal Behavioral } \\
\text { Assessment Scale }\end{array}$ & $\begin{array}{l}\text { The intervention involved a single in-person demonstration of the Neonatal Behavioral Assessment } \\
\text { Scale. Immediate and continuing feedback, as well as a terminal summary statement, was provided } \\
\text { to parents during the demonstration. A manualized curriculum was not used. The intervention was } \\
\text { delivered 2-3 d postpartum, usually before hospital discharge, by Beal. }{ }^{52}\end{array}$ \\
\hline Field et al, ${ }^{53} 2008$ & $\mathrm{~N} / \mathrm{A}$ & $\begin{array}{l}\text { The intervention involved fathers learning how to conduct a pregnancy massage, a DVD on the massage, } \\
\text { and fathers delivering 20-min massages to the mother twice a wk for } 16 \text { wk. Each session included } \\
\text { the father massaging the mother's head, neck, back, arms, hands, and feet. A manualized curriculum } \\
\text { was not used. The intervention was delivered between the second trimester and } 32 \text { wk of pregnancy } \\
\text { by trained massage therapists. Mode of delivery involved DVD and in-person sessions. }\end{array}$ \\
\hline Smith et al, ${ }^{55} 2016$ & Centering Pregnancy & $\begin{array}{l}\text { The intervention was a group-based prenatal care program and case management. The prenatal class } \\
\text { examined nutrition, exercise, relaxation, childbirth preparation, infant care and feeding, postpartum } \\
\text { care, communication, relationships, and parenting. Case management involved assessment of } \\
\text { participant needs and identification of resources. The intervention used handouts, worksheets, and } \\
\text { skill-building exercises to enhance group sessions. Use of a manualized curriculum was unclear. The } \\
\text { intervention seems to have been delivered during pregnancy. The intervention was delivered by male } \\
\text { social workers. Mode of delivery involved in-person sessions. }\end{array}$ \\
\hline
\end{tabular}

DVD, digital video disc; e-health, electronic health; N/A, not applicable.

groups, birthing classes, and at birth compared with control group fathers. Additionally, mothers in a qualitative study of a relationship program ${ }^{51}$ reported greater commitment from their male partners as well as willingness from male partners to discuss preparations for childbirth and future involvement. However, these studies were rated at high RoB. In contrast, the results of an RCT of a clinical intervention ${ }^{52}$ with a high RoB revealed no effects on father involvement in caregiving.
Father's Knowledge, Attitudes, and Mental Health

\section{Father's Parenting Knowledge}

Researchers for 3 quantitative studies (1 RCT, 1 quasi-experimental, and 1 nonexperimental) examined fathers' parenting knowledge outcomes. ${ }^{35,39,41}$ All 3 programs had significant effects on fathers' knowledge of infant care and/or development or pregnancy and prenatal parent knowledge.35,39,41 However, these studies were deemed to be at high RoB because of methodological limitations, such as ambiguity in when pretest and posttest were administered (eg, whether during pregnancy or how many months at postpartum).

\section{Father's Attitudes and Parenting Self-Efficacy}

Researchers for 3 quantitative studies (1 RCT, 1 quasi-RCT, and 1 nonexperimental) and 1 qualitative study examined father's attitudes and parenting self-efficacy outcomes. ${ }^{40,50-52}$ The results of 


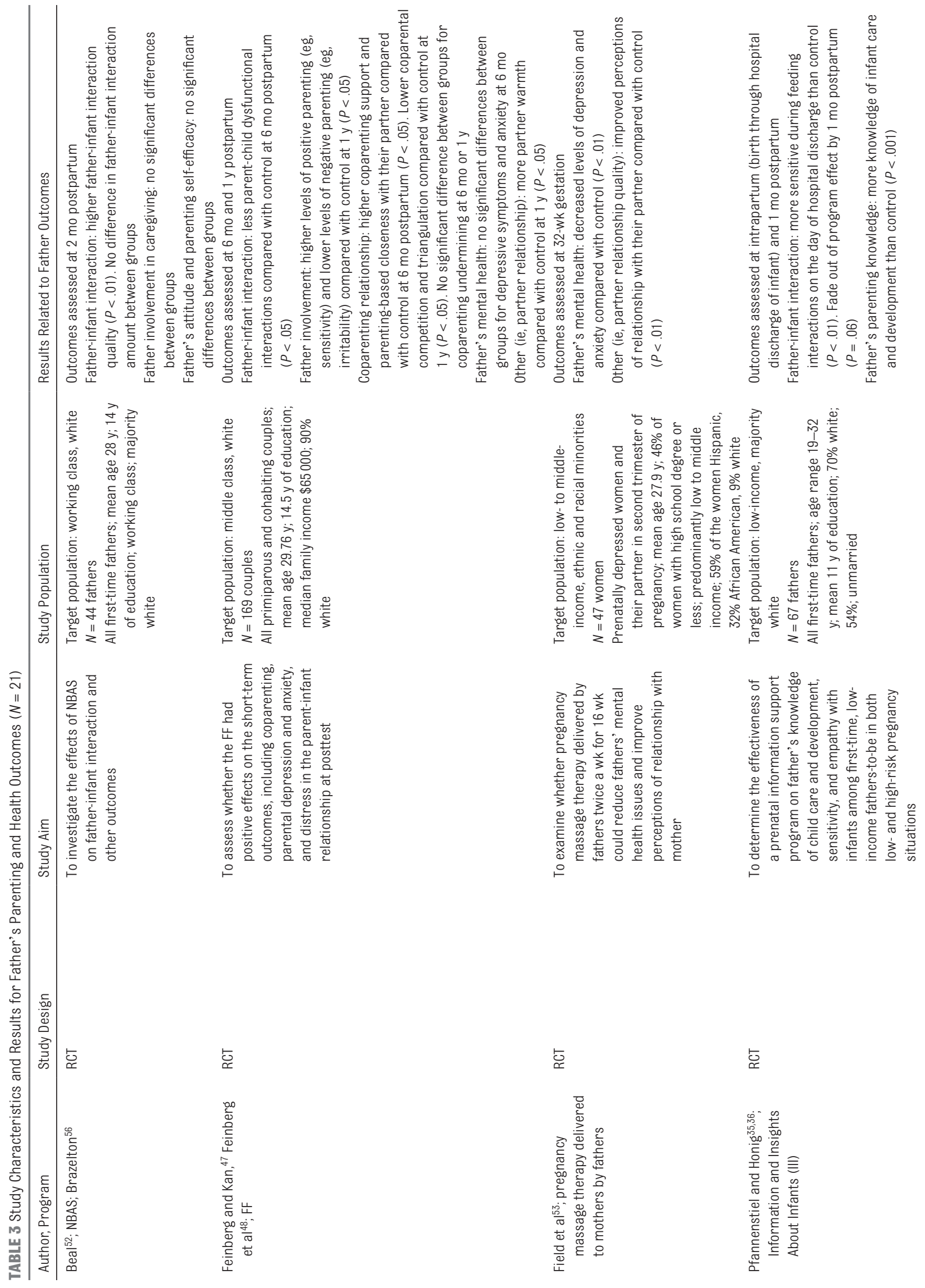




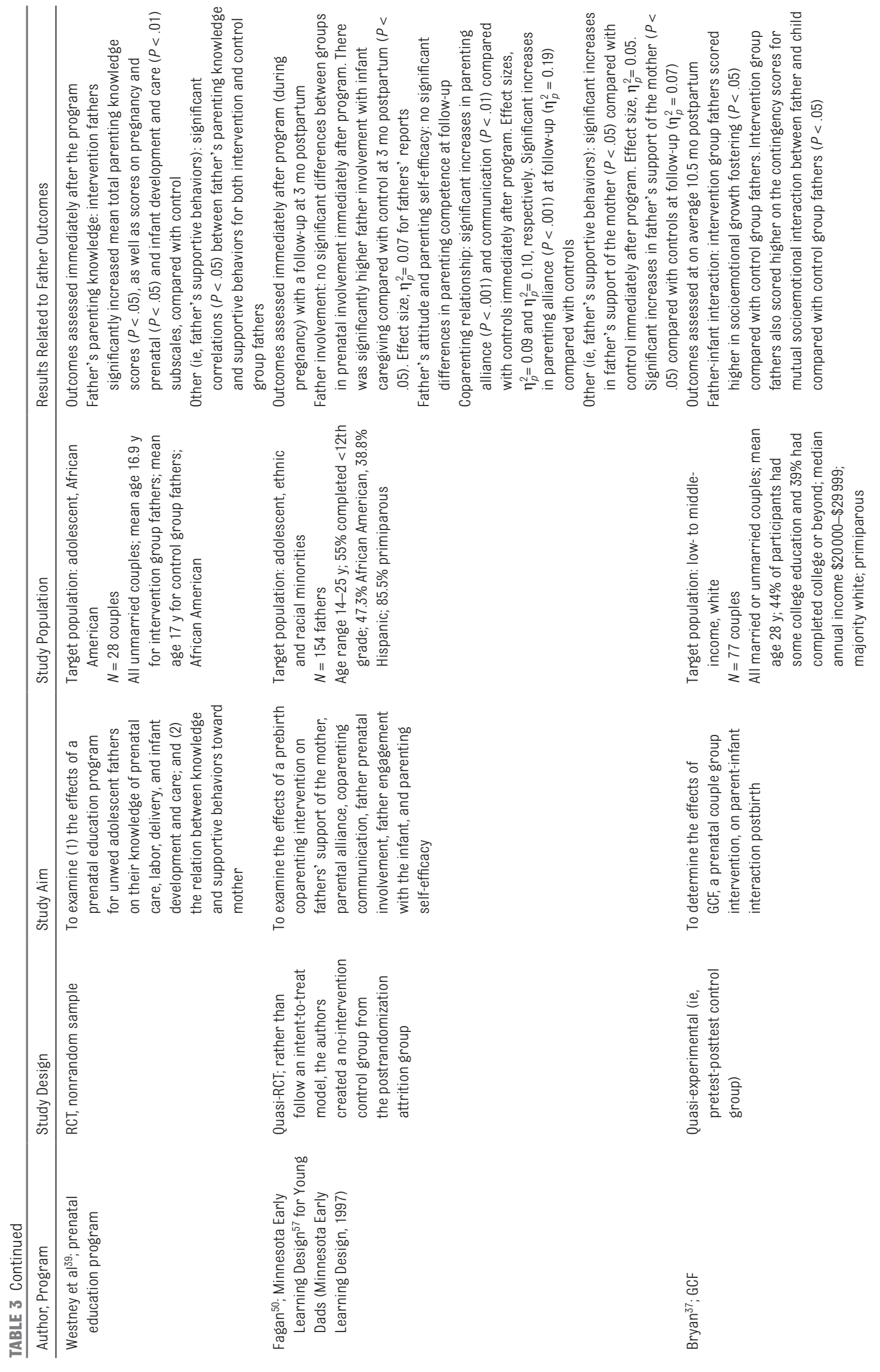




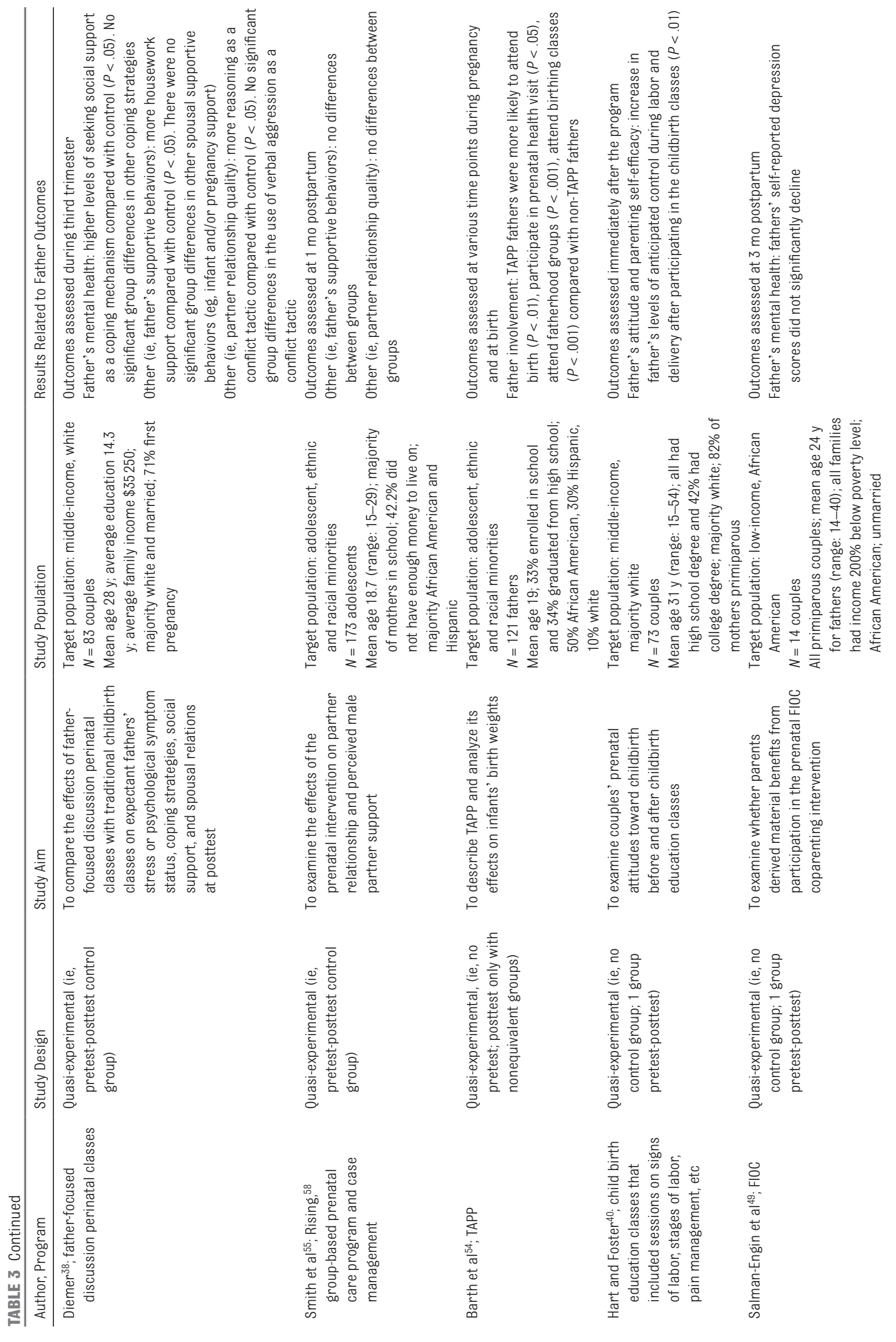




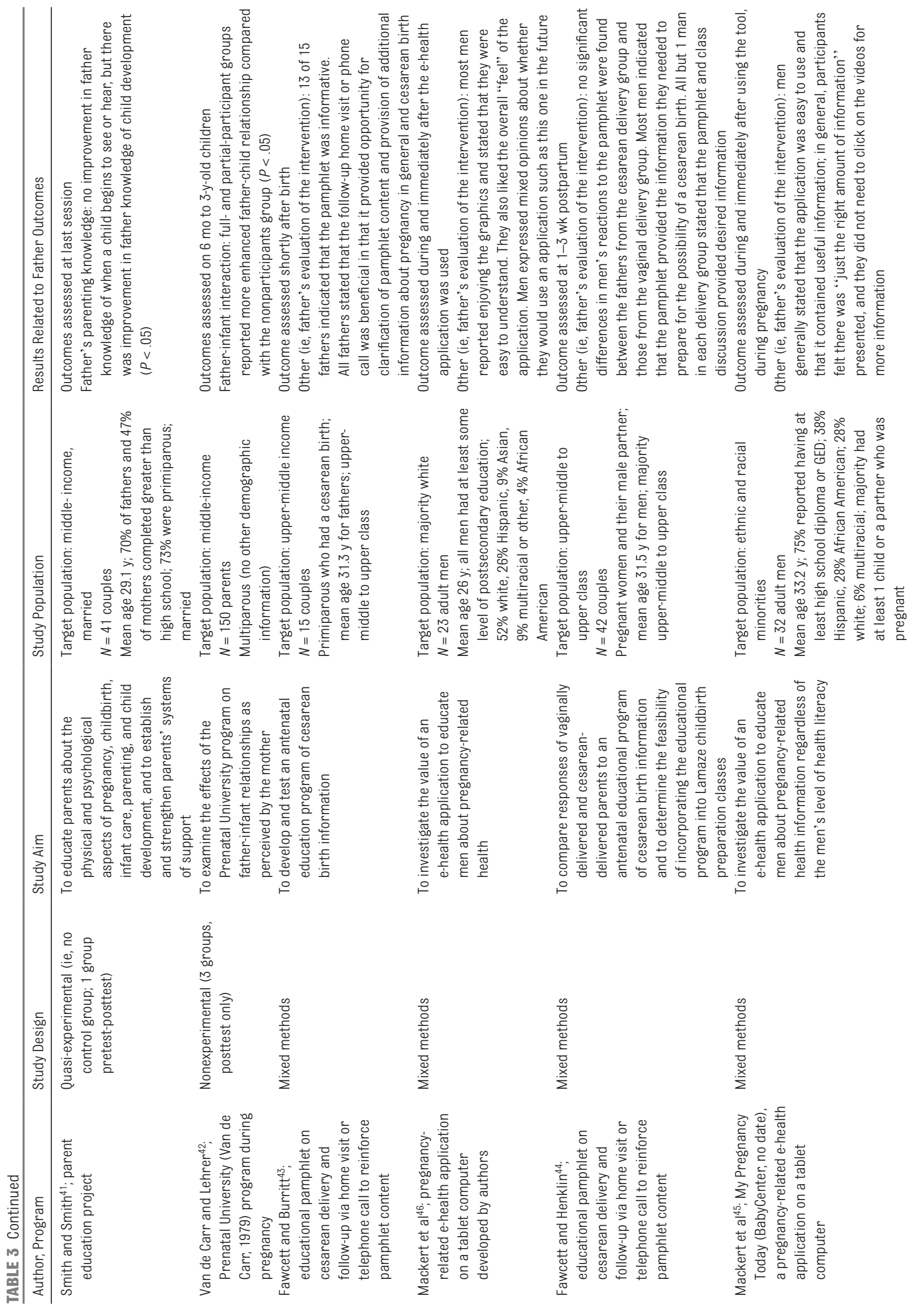




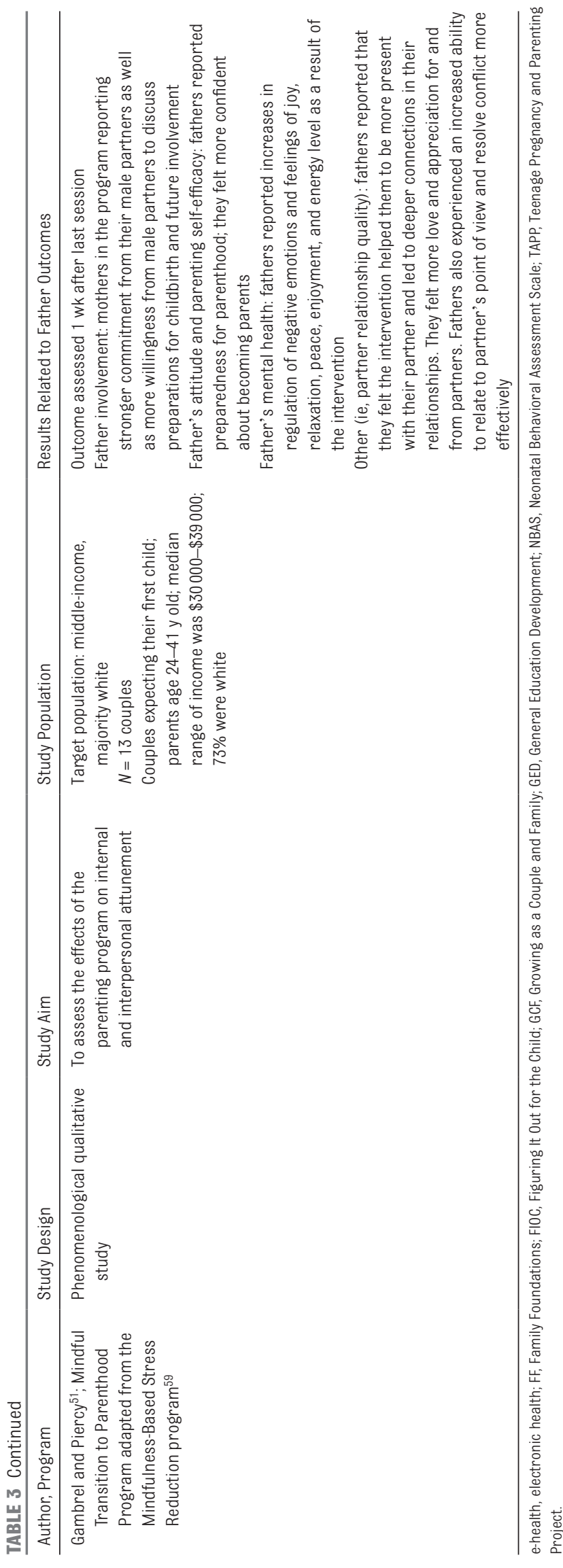

a quasi-RCT of a coparenting program $^{50}$ revealed no program effects on fathers' sense of parenting competence at 3 months postpartum. This was the only study considered to have low RoB. Similarly, the results of an RCT of a clinical program ${ }^{52}$ revealed no program effects on fathers' attitudes toward caregiving at 2 months postpartum. In contrast, the results of 2 nonexperimental studies ${ }^{40,51}$ revealed positive effects in the prepartum period. Specifically, the results of 1 nonexperimental study of a general education program ${ }^{40}$ revealed a significant increase from pretest to posttest in fathers' level of anticipated control during labor and delivery. The results of another study, which was a qualitative study of a relationship program, ${ }^{51}$ revealed that fathers reported feelings of confidence and preparedness for fatherhood before the birth of the infant.

\section{Father's Mental Health}

Researchers for 4 quantitative (2 RCTs and 2 quasi-experimental) and 1 qualitative studies examined fathers' mental health outcomes. ${ }^{38,47,49,53}$ The results of a low RoB quasi-experimental study of a general education program ${ }^{38}$ revealed significant increases in fathers' social support seeking related to pregnancy-related stressors measured during the third trimester. It was reported in a qualitative study of a relationship program intervention that occurred during pregnancy ${ }^{51}$ that fathers felt improved emotion regulation and greater relaxation, peace, and enjoyment after the intervention. In a high RoB RCT of a massage-based program, ${ }^{53}$ significant decreases in fathers' depression and anxiety levels at 36 weeks of pregnancy were reported. In contrast, the results of 2 studies of coparenting programs $\mathrm{s}^{47,49}$ did not reveal significant effects on fathers' mental health in the 
TABLE 4 RoB Assessment for Included Studies

\begin{tabular}{|c|c|c|c|c|c|}
\hline Author, y & Participant Selection & Blinding of Outcome & $\begin{array}{c}\text { Incomplete Outcome } \\
\text { Data }\end{array}$ & Selective Reporting & Cumulative Risk Value \\
\hline Barth et al, ${ }^{54} 1988$ & Low & Low & Unclear & High & 2 \\
\hline Beal, ${ }^{52} 1989$ & Unclear & Low & Unclear & Low & 2 \\
\hline Bryan, $^{37} 2000$ & Low & High & Low & High & 2 \\
\hline Diemer, ${ }^{38} 1997$ & Low & Unclear & Low & Low & 3 \\
\hline Fagan, ${ }^{50} 2008$ & Low & Low & Low & Low & 4 \\
\hline Fawcett and Burritt, ${ }^{43} 1985$ & Unclear & Unclear & Unclear & Unclear & 0 \\
\hline Fawcett and Henklin, ${ }^{44} 1987$ & Unclear & Low & High & Low & 2 \\
\hline Feinberg and Kan, ${ }^{47} 2008$ & Low & High & Low & Low & 3 \\
\hline Feinberg et al, ${ }^{48} 2009$ & Low & Low & Unclear & Low & 3 \\
\hline Field et al, ${ }^{53} 2008$ & Low & High & Unclear & Low & 2 \\
\hline Gambrel and Piercy, ${ }^{51} 2015$ & Unclear & Unclear & Low & Low & 2 \\
\hline Hart and Foster, ${ }^{40} 1997$ & Low & Unclear & Unclear & Low & 2 \\
\hline Mackert et al, ${ }^{45} 2015$ & Unclear & Unclear & Low & Low & 2 \\
\hline Mackert et al, ${ }^{46} 2017$ & Unclear & Unclear & Low & Low & 2 \\
\hline Pfannenstiel and Honig,, 1991 & Low & Low & High & High & 2 \\
\hline Pfannenstiel, and Honig, 351995 & Low & High & Unclear & High & 1 \\
\hline Salman-Engin et al, ${ }^{49} 2017$ & Unclear & Unclear & Unclear & Low & 1 \\
\hline Smith and Smith, ${ }^{41} 1978$ & High & Unclear & Unclear & High & 0 \\
\hline Smith et al, ${ }^{55} 2016$ & High & Unclear & High & Low & 1 \\
\hline Van de Carr and Lehrer, ${ }^{42} 1986$ & Low & Unclear & High & Low & 2 \\
\hline Westney et al, ${ }^{39} 1988$ & Unclear & Unclear & Unclear & Unclear & 0 \\
\hline
\end{tabular}

Low risk $=1$; high risk $=0$; unclear risk $=0$. Each study could receive up to a cumulative risk value of 4 . Studies scoring a cumulative risk value of $\leq 2$ are considered to possess high RoB

TABLE 5 Recommendations for Father-Inclusive Perinatal Parent Education Programs

\footnotetext{
1. Father-inclusive perinatal parent education programs should employ a family systems approach by involving both the father and mother 60

2. When possible, programs should employ men or male-female teams as facilitators 47,48

3. Consider employing facilitators that mirror the characteristics (eg, ethnicity or race, age, culture, language) of the fathers being served ${ }^{61,62}$

4. Train facilitators to welcome, engage, and directly speak with fathers $6,15,63$

5. Include father-only group sessions to provide a safe space for men to express their feelings, combat social isolation, and receive peer support 38,60

6. Use a strengths-based perspective by focusing and building on the positive characteristics fathers bring to parenting ${ }^{60,63,64}$

7. Implement programs that are tailored to fathers' parenting needs (for example, programs that are sensitive to the needs of nonresidential fathers) ${ }^{62,64}$

8. Consider whether aspects of the clinical environment are welcoming and friendly to fathers (eg, pictures of men with infants, magazines for fathers and mothers in the waiting room) ${ }^{65}$

9. Include in the curriculum content related to improving the coparenting relationship between the father and mother ${ }^{15,60}$

10. Allow room for fathers and mothers to discuss topics that are most relevant to their parenting circumstances and needs ${ }^{60}$

11. Develop special events that celebrate fathers and fatherhood 64

12. Provide literature, such as brochures, to fathers that contain educational content related to infant care and development, stress management, and community-based resources ${ }^{64}$

13. Educate mothers about the importance of father involvement on child development and well-being ${ }^{6}$

14. Consider providing child care, financial incentives, meals, and/or transportation 60,65

15. Deliver programs during times (eg, evenings or weekends) when it is convenient for fathers to participate ${ }^{62,64}$

16. Offer parent education along with other services, such as employment assistance, General Education Development test preparation, and support to address mental health and substance abuse problems ${ }^{65,66}$

17. When welcomed, use mobile technology, such as text messages, as reminders for program sessions, check-ins, and follow-ups (especially after a father misses a session) ${ }^{60}$
}

postpartum period. More specifically, the results of a quasi-experimental study of a coparenting program ${ }^{49}$ (high RoB) revealed no program effects on fathers' depressive scores at 3 months postpartum. Similarly, the results of an RCT of another coparenting program ${ }^{47}$ (low RoB) revealed no effects on fathers' depressive symptoms and anxiety at 6 months postpartum.

\section{Father-Mother Relationship}

Father's Coparenting Relationship With Mother

Researchers for 3 quantitative studies (2 RCTs and 1 quasi-RCT) evaluated 2 coparenting programs that assessed father's coparenting relationship with the mother. $47,48,50$ The results of 2 RCTs of the same coparenting program ${ }^{47,48}$ revealed increased fathers' coparenting support $(d=0.54)$ and closeness with the mother $(d=0.44)$ at 6 months postpartum. Intervention group fathers also reported reduced coparenting competition $(d=0.36)$ and triangulation $(d=0.28)$ when the child was 1 year old. ${ }^{4,48}$ The results of a quasi-RCT of another coparenting program ${ }^{50}$ revealed moderate effects on fathers' reports 
of parenting alliance $\left(\eta_{p}^{2}=0.09\right)$ and coparenting communication $\left(\eta_{p}^{2}=\right.$ 0.10 ) at posttest during pregnancy. The same program ${ }^{50}$ had a greater effect on parenting alliance at 3 months postpartum $\left(\eta_{p}^{2}=0.19\right)$.

\section{Partner Relationship Quality}

Researchers for 4 quantitative studies (2 RCTs and 2 quasi-experimental) and 1 qualitative study examined couples' partner relationship quality outcomes. ${ }^{38,48,51,53,55}$ The results of an RCT of a coparenting program ${ }^{48}$ revealed positive intervention effects on men's warmth toward their female partner when the child was 1 year old. The results of a quasi-experimental study of a general education program ${ }^{38}$ revealed positive effects on men's use of reasoning measured during the third trimester. Both studies were considered to have low RoB.

Researchers for a qualitative study of a relationship program ${ }^{51}$ reported that fathers felt the intervention helped them establish deeper connections in their relationships, feel more love and appreciation toward their partner, relate to their partner's point of view, and resolve conflict more effectively during pregnancy. Researchers for a high RoB RCT of a massage-based clinical program ${ }^{53}$ also reported significant increases in both fathers' and mothers' perceptions of partner relationship quality at 36 weeks of pregnancy. In contrast, a high RoB quasi-experimental study of a case management program for expectant adolescent parents ${ }^{55}$ found no effects on partner relationship quality at 1 month postpartum.

\section{Father's Supportive Behaviors}

Researchers for 3 quantitative studies (1 quasi-RCT and 2 quasiexperimental) examined fathers' supportive behavior outcomes. ${ }^{38,50,55}$ The results of a quasi-randomized study of a coparenting program ${ }^{50}$ revealed moderate program effects on both fathers' $\left(\eta_{p}^{2}=0.05\right)$ and mothers' $\left(\eta_{p}^{2}=0.07\right)$ reports of fathers' supportive behaviors toward the mother at posttest during pregnancy. Similarly, the results of a quasi-experimental study of a general education program ${ }^{38}$ revealed a significant positive effect on fathers' support with housework in the third trimester. Both of these studies had low RoB. In contrast, a high RoB quasi-experimental study of a case management program for expectant adolescent parents ${ }^{55}$ found no effects on fathers' support for the mother at 1 month postpartum.

\section{DISCUSSION}

To the best of our knowledge, we are the first to examine, in a systematic review, US-based father-inclusive perinatal parent education programs, and whether such programs are associated with important father outcomes. Overall, we demonstrated in our review of the literature that there are few father-inclusive programs during the perinatal period. We found only 19 different father-inclusive perinatal interventions evaluated in the literature despite considering a broad range of outcomes and taking a comprehensive approach to our review, with no limitations on publication date and research methodology. In addition to the small number of interventions, we found the general state of this research base to be weak, with only 4 out of the 21 studies rated as having low RoB. These results are consistent with previous systematic reviews on father-inclusive parent education programs. ${ }^{15,22,24,25,60}$ For example, in their review of the literature on father involvement programs for lowincome families, Pruett et al ${ }^{60}$ noted few privately and federally funded programs have yielded promising outcomes. Suto et $\mathrm{al}^{24}$ found similar results in that their review revealed a lack of evidence for the effectiveness of father-focused prenatal childbirth education programs in protecting against paternal postpartum depression and improving partner relationship quality.

Given the weak evidence base, we were unable to draw firm conclusions about the effectiveness of early father-inclusive parent education programs. Nevertheless, there was some limited (ie, primarily based on 3 low RoB studies) evidence to suggest that early father-inclusive parent education programs may improve outcomes related to father involvement, coparenting relationship, partner relationship quality, father's mental health, and father's supportive behaviors. On the other hand, there was generally a lack of evidence for program effects on father-infant interaction, father's parenting knowledge, and father's attitudes and parenting self-efficacy.

Results from the RoB assessment suggested that 2 coparenting programs (Minnesota Early Learning Design for Young Dads ${ }^{50}$ and Family Foundations ${ }^{47,48}$ ) as well as a general perinatal education program developed by Diemer ${ }^{38}$ may serve as the best set of father-inclusive evidence-based interventions given their rigorous study designs, low levels of bias, promising outcomes, and methods of implementing the intervention that appeal to fathers. For example, the Minnesota Early Learning Design for Young Dads program ${ }^{50}$ not only used a manualized coparenting curriculum but also aimed to provide positive role models to adolescent fathers by employing previous male participants as facilitators. Family Foundations ${ }^{47,48}$ also used a manualized coparenting curriculum as well as a male-female facilitator team to implement interactive skillsbased group sessions. Diemer ${ }^{38}$ developed a general perinatal education program that allowed for a men-only and women-only group for the first session so that fathers 
can share their feelings, combat their sense of isolation, and experience peer support. In subsequent mixedsex groups, veteran childbirth educators were trained to ask questions and share comments directly with fathers to encourage participation.

\section{Emerging Intervention Practices}

As noted, there are few fatherinclusive perinatal parent education programs. However, innovative perinatal programs are emerging to help fill this void. ${ }^{67-71}$ One intervention approach that shows promise is the use of home visitation program "add-ons" that target fathers. Home visitation models, such as the Nurse Family Partnership, that target low-income mothers are recognized as having lasting positive effects on the health and well-being of children. ${ }^{69}$ The Dads Matter program ${ }^{72}$ has trained female home visitors to work with fathers during their home visits, thus expanding the program to include working with mothers and fathers. Preliminary evidence from an RCT of the Dads Matter program suggested that the program was associated with increases in fathers' reports of attitudes regarding the values of their contributions to children's wellbeing, mothers' reports of support from fathers, and both parents' reports of father engagement. ${ }^{70,71}$

Another promising approach is facilitating positive father-child interactions. The Baby Elmo Program ${ }^{73}$ is a brief intervention originally designed for incarcerated teenage fathers. It uses a theoretically driven intervention approach and interactive sessions to help fathers understand their infant's emotional needs and thus support positive father-child interactions. ${ }^{73,74}$ The program is now being tested as an RCT with community-based samples of low-income fathers. ${ }^{75,76}$

Supporting Father Involvement, a group-based relationship strengthening program that has been successful in promoting father involvement, ${ }^{77,78}$ is currently being tested with high-risk couples involved in the child welfare system. ${ }^{60}$ In hospital settings, Conscious Fathering, an early father involvement program by Dorsey, ${ }^{79}$ has been providing expectant men with infant care skills and education on responsive fathering.

\section{Clinical Implications}

Despite the emergence of several noteworthy programs, research to develop and test early fatherinclusive interventions has generally not kept pace with demographic trends showing increased father involvement and the important roles fathers play in promoting optimal child development. This issue likely persists because of multiple factors, ${ }^{80,81}$ including clinicians being unwilling or inadequately trained to engage fathers, ${ }^{15,63}$ programs not being tailored to men's parenting needs, ${ }^{14,61,65}$ and maternal gatekeeping preventing men's active involvement in programs during pregnancy. ${ }^{82,83}$ These factors may help explain some of the reasons for men feeling marginalized from health care settings ${ }^{84,85}$ and men's perceptions that there is little role for their involvement during pregnancy and infancy. ${ }^{86-88}$

Clinicians play a key role in promoting early father involvement because they are likely to be among the first to come in contact with mothers and fathers expecting an infant or recently had an infant. ${ }^{6,89}$ As such, it is important for clinicians to consider fathers when developing or implementing programs for parents as well as to employ practices that would support fathers to be engaged with the mother and infant across the perinatal period (Table 5). Yogman and Garfield ${ }^{6}$ have provided clinical recommendations, including acknowledging fathers' presence when they attend health care visits, welcoming fathers directly, and soliciting their opinions when appropriate. Research suggests that many fathers do attend early health care visits, and positive interactions with health care providers are important in fathers' evaluations of their experiences with the health care system and their willingness to participate in future visits. ${ }^{90}$ Clinicians can highlight fathers as important contributors to their children's health and well-being by educating men on the roles they play in their children's early years.

Clinicians can also play a key role in promoting positive coparenting and partner relationship quality by openly discussing with fathers and mothers the changes they are likely to experience during pregnancy and after the birth of the infant. Research suggests that men typically rely on women for parenting knowledge and thus could benefit from having positive male role models. ${ }^{91}$ In this regard, male health care staff may be effective in directly engaging fathers, educating them about infant care and child development, and providing anticipatory guidance. When appropriate and welcomed, fathers can be encouraged to provide supportive behaviors to mothers and assume more active child care roles.

Fathers' mental health is another area of concern for clinicians. Research reveals that elevated paternal postpartum depression is associated with negative fathering behaviors and subsequent child outcomes. ${ }^{92-94}$ Yet, paternal depression is rarely acknowledged in health care settings. Clinicians can adopt both a familycentered care ${ }^{95}$ and family systems ${ }^{96}$ approach, screening both mothers and fathers for depression at pediatric settings to improve the health of men, their children, and their families across the perinatal period. 6,92

\section{Limitations of the Evidence Quality}

The majority of studies in this systematic review were deemed 
to possess high RoB, suggesting that the general quality of evidence supporting father-inclusive parent education programs is weak. This systematic review may also be limited by the file drawer problem. ${ }^{97}$ Because we included only published studies, it is possible that unpublished research of father-inclusive interventions was missed. Furthermore, publication bias may result in some studies reporting significant results only, thus biasing the systematic review toward significant findings. We note that this review is exclusively focused on US-based programs to complement existing research conducted internationally. ${ }^{15,23}$ Most studies in this systematic review implemented interventions within a clinical setting, preventing the generalization of findings to other contexts. With several exceptions, ${ }^{43,44,47,48,50}$ most studies examined program effects at a single time point without followups. As such, the existing evidence does not allow for understanding long-term program effects. Variability in the operationalization and measurement of study outcomes, small sample sizes, and other intervention characteristics also contribute to the weak evidence base. The authors of previous systematic reviews have noted similar methodological limitations. ${ }^{15,22,24}$

\section{CONCLUSIONS}

In this systematic review, we examined the current state of the literature on father-inclusive perinatal parent education programs. There were several notable findings. First, the overall evidence base revealed that there were few programs in which fatherhood is targeted across the perinatal period. This underscores the need for evidence-based interventions in which fathers are supported during this important period of child development. Second, available programs were associated with increased father involvement, coparenting relationship, partner relationship quality, father's mental health, and father's supportive behaviors. Third, evidence for program effects on father-infant interaction, father's parenting knowledge, and father's attitudes and parenting self-efficacy was inconclusive. Finally, the Minnesota Early Learning Design for Young Dads $^{50}$ and Family Foundations ${ }^{47,48}$ coparenting programs and Diemer's ${ }^{38}$ perinatal education program emerged as the best evidence-based interventions. Collectively, these results suggest that although some early fatherinclusive parent education programs are promising, more rigorous evaluation research is necessary to examine program effects on father outcomes. Clinicians can help promote optimal outcomes for children and families by involving men in early parent education programs and health care visits across the perinatal period.

\section{ACKNOWLEDGMENTS}

Thank you to Muzi Lin for her contribution in compiling articles included in this article. Thank you to Drs. Brenda L. Volling and Andrew Grogan-Kaylor for their helpful comments on an earlier version of this article.

\section{ABBREVIATIONS}

CINAHL: Cumulative Index to Nursing and Allied Health Literature

PRISMA: Preferred Reporting Items for Systematic Reviews and Meta-Analyses

RCT: randomized controlled trial RoB: risk of bias

RoBANS: risk of bias assessment tool for nonrandomized study

Accepted for publication Apr 11, 2018

Address correspondence to Joyce Y. Lee, MSW, School of Social Work, University of Michigan, 1080 South University Ave., Ann Arbor, MI 48109. E-mail: joyceyl@ umich.edu

PEDIATRICS (ISSN Numbers: Print, 0031-4005; Online, 1098-4275).

Copyright @ 2018 by the American Academy of Pediatrics

FINANCIAL DISCLOSURE: The authors have indicated they have no financial relationships relevant to this article to disclose.

FUNDING: No external funding.

POTENTIAL CONFLICT OF INTEREST: The authors have indicated they have no potential conflicts of interest to disclose.

\section{REFERENCES}

1. Bianchi SM, Robinson JP, Milkie MA. Changing Rhythms of American Family Life. New York, NY: Russell Sage Foundation; 2007

2. Alio AP, Mbah AK, Grunsten RA, Salihu $\mathrm{HM}$. Teenage pregnancy and the influence of paternal involvement on fetal outcomes. J Pediatr Adolesc Gynecol. 2011;24(6):404-409

3. Alio AP, Mbah AK, Kornosky JL, Wathington D, Marty PJ, Salihu HM. Assessing the impact of paternal involvement on racial/ethnic disparities in infant mortality rates. J Community Health. 2011;36(1):63-68

4. Cabrera NJ, Tamis-LeMonda CS. Handbook of Father Involvement: 
Multidisciplinary Perspectives. 2nd ed. New York, NY: Taylor \& Francis; 2013

5. Lamb ME. The Role of the Father in Child Development. 5th ed. Hoboken, NJ: John Wiley \& Sons; 2010

6. Yogman M, Garfield CF; Committee on Psychosocial Aspects of Child and Family Health. Fathers' roles in the care and development of their children: the role of pediatricians. Pediatrics. 2016;138(1):e20161128

7. De Luccie M. Predictors of paternal involvement and satisfaction. Psychol Rep. 1996;79(3, pt 2):1351-1359

8. Almeida DM, Galambos NL. Examining father involvement and the quality of father-adolescent relations. J Res Adolesc. 1991;1(2):155-172

9. Snarey JR. How Fathers Care for the Next Generation: A Four-Decade Study. Cambridge, MA: Harvard University Press; 1993

10. Bellamy JL, Thullen M, Hans S. Effect of low-income unmarried fathers' presence at birth on involvement. J Marriage Fam. 2015;77(3):647-661

11. Carlson MJ, McLanahan SS, BrooksGunn J. Coparenting and nonresident fathers' involvement with young children after a nonmarital birth. Demography. 2008;45(2):461-488

12. Barnett RC, Marshall NL, Pleck JH. Men's multiple roles and their relationship to men's psychological distress. J Marriage Fam. 1992;54 (2):358-367

13. Pleck JH. Paternal involvement: levels, sources, and consequences. In: Lamb ME, ed. The Role of the Father in Child Development. 3rd ed. New York, NY: John Wiley \& Sons; 1997:66-103

14. Lundahl BW, Tollefson D, Risser $\mathrm{H}$, Lovejoy MC. A meta-analysis of father involvement in parent training. Res Soc Work Pract. 2008;18(2):97-106

15. Panter-Brick C, Burgess A, Eggerman M, McAllister F, Pruett K, Leckman JF. Practitioner review: engaging fathersrecommendations for a game change in parenting interventions based on a systematic review of the global evidence. J Child Psychol Psychiatry. 2014;55(11):1187-1212

16. Bond MJ. The missing link in $\mathrm{MCH}$ : paternal involvement in pregnancy outcomes. Am J Mens Health. 2010;4(4):285-286

17. Dudgeon MR, Inhorn MC. Men's influences on women's reproductive health: medical anthropological perspectives. Soc Sci Med. 2004;59(7):1379-1395

18. Gerein N, Mayhew S, Lubben M. A framework for a new approach to antenatal care. Int J Gynaecol Obstet. 2003;80(2):175-182

19. Takehara K, Suto M, Kakee N, Tachibana Y, Mori R. Prenatal and early postnatal depression and child maltreatment among Japanese fathers. Child Abuse Negl. 2017;70:231-239

20. Brown J, Cohen P, Johnson JG, Salzinger S. A longitudinal analysis of risk factors for child maltreatment: findings of a 17-year prospective study of officially recorded and self-reported child abuse and neglect. Child Abuse Negl. 1998;22(11):1065-1078

21. Guterman NB, Lee $Y$. The role of fathers in risk for physical child abuse and neglect: possible pathways and unanswered questions. Child Maltreat. 2005;10(2):136-149

22. Magill-Evans J, Harrison MJ, Rempel G Slater L. Interventions with fathers of young children: systematic literature review. J Adv Nurs. 2006;55(2):248-264

23. Amin NAL, Tam WSW, Shorey S. Enhancing first-time parents' selfefficacy: a systematic review and metaanalysis of universal parent education interventions' efficacy. Int J Nurs Stud. 2018;82:149-162

24. Suto M, Takehara K, Yamane $Y$, Ota E. Effects of prenatal childbirth education for partners of pregnant women on paternal postnatal mental health and couple relationship: a systematic review. J Affect Disord. 2017;210:115-121

25. Holmes EK, Galovan AM, Yoshida K, Hawkins AJ. Meta-analysis of the effectiveness of resident fathering programs: are family life educators interested in fathers? Fam Relat. 2010;59(3):240-252

26. Martin JA, Hamilton BE, Osterman MJK, Driscoll AK, Mathews TJ. Births: final data for 2015. Natl Vital Stat Rep. 2017:66(1):1
27. Jones J, Mosher WD. Fathers' involvement with their children: United States, 2006-2010. Natl Health Stat Rep. 2013; (71):1-21

28. Liberati A, Altman DG, Tetzlaff J, et al. The PRISMA statement for reporting systematic reviews and meta-analyses of studies that evaluate health care interventions: explanation and elaboration. PLOS Med. 2009;6(7):e1000100

29. Moher D, Liberati A, Tetzlaff J, Altman DG; PRISMA Group. Preferred reporting items for systematic reviews and meta-analyses: the PRISMA statement. PLoS Med. 2009;6(7):e1000097

30. Thomson Reuters. EndNote X6. 2013. Available at: https://endnote.com/ support/online-user-manual/x6. Accessed July 28, 2017

31. Popay J, Roberts H, Sowden A, et al Guidance on the Conduct of Narrative Synthesis in Systematic Reviews: A Product From the ESRC Methods Programme. Lancaster, United Kingdom: Lancaster University; 2006

32. Ryan R; Cochrane Consumers and Communication Review Group. Cochrane Consumers and Communication Review Group: data synthesis and analysis. 2013. Available at: http://cccrg.cochrane.org/sites/ cccrg.cochrane.org/files/public/ uploads/Analysis.pdf. Accessed July 30 2017

33. Kim SY, Park JE, Lee YJ, et al. Testing a tool for assessing the risk of bias for nonrandomized studies showed moderate reliability and promising validity. J Clin Epidemiol. 2013;66(4):408-414

34. Higgins JPT, Green S, eds. Cochrane Handbook for Systematic Reviews of Interventions. London, United Kingdom: The Cochrane Collaboration; 2009

35. Pfannenstiel AE, Honig AS. Effects of a prenatal "Information and Insights about Infants" program on the knowledge base of first-time low-education fathers one month postnatally. Early Child Dev Care. 1995;111(1):87-105

36. Pfannenstiel AE, Honig AS. Prenatal intervention and support for lowincome fathers. Infant Ment Health $\mathrm{J}$. 1991;12(2):103-115 
37. Bryan AA. Enhancing parent-child interaction with a prenatal couple intervention. MCN Am J Matern Child Nurs. 2000;25(3):139-144; quiz 145

38. Diemer GA. Expectant fathers: influence of perinatal education on stress, coping, and spousal relations. Res Nurs Health. 1997;20(4):281-293

39. Westney OE, Cole OJ, Munford TL. The effects of prenatal education intervention on unwed prospective adolescent fathers. J Adolesc Health Care. 1988;9(3):214-218

40. Hart MA, Foster SN. Couples' attitudes toward childbirth participation: relationship to evaluation of labor and delivery. J Perinat Neonatal Nurs. 1997;11(1):10-20

41. Smith D, Smith HL. Toward improvements in parenting: a description of prenatal and postpartum classes with teaching guide. JOGN Nurs. 1978;7(6):22-27

42. Van de Carr R, Lehrer M. Enhancing early speech, parental bonding and infant physical development using prenatal intervention in standard obstetric practice. J Prenat Perinat Psychol Health. 1986;1(1):20-30

43. Fawcett J, Burritt J. An exploratory study of antenatal preparation for cesarean birth. J Obstet Gynecol Neonatal Nurs. 1985;14(3):224-230

44. Fawcett J, Henklein JC. Antenatal education for cesarean birth: extension of a field test. $J$ Obstet Gynecol Neonatal Nurs. 1987;16(1):61-65

45. Mackert M, Guadagno M, Donovan E, Whitten P. Including men in prenatal health: the potential of e-health to improve birth outcomes. Telemed J E Health. 2015;21(3):207-212

46. Mackert M, Guadagno M, Lazard A, et al. Engaging men in prenatal health promotion: a pilot evaluation of targeted e-health content. Am J Men Health. 2017;11(3):719-725

47. Feinberg ME, Kan ML. Establishing family foundations: intervention effects on coparenting, parent/infant wellbeing, and parent-child relations. J Fam Psychol. 2008;22(2):253-263

48. Feinberg ME, Kan ML, Goslin MC. Enhancing coparenting, parenting, and child self-regulation: effects of family foundations 1 year after birth [published correction appears in Prev Sci. 2009;10(3):286]. Prev Sci. 2009;10(3):276-285

49. Salman-Engin S, Little T, Gaskin-Butler V, McHale JP. A prenatal coparenting intervention with unmarried father-mother dyads: fidelity of intervention delivery by male-female community mentor teams. J Nurs Res. 2017;25(3):240-250

50. Fagan J. Randomized study of a prebirth coparenting intervention with adolescent and young fathers. Fam Relat. 2008;57(3):309-323

51. Gambrel LE, Piercy FP. Mindfulnessbased relationship education for couples expecting their first child-part 2: phenomenological findings. J Marital Fam Ther. 2015;41(1):25-41

52. Beal JA. The effect on father-infant interaction of demonstrating the neonatal behavioral assessment scale. Birth. 1989;16(1):18-22

53. Field T, Figueiredo B, Hernandez-Reif M, Diego M, Deeds 0, Ascencio A. Massage therapy reduces pain in pregnant women, alleviates prenatal depression in both parents and improves their relationships. J Bodyw Mov Ther. 2008;12(2):146-150

54. Barth RP, Claycomb M, Loomis A. Services to adolescent fathers. Health Soc Work. 1988;13(4):277-287

55. Smith PB, Buzi RS, Kozinetz CA, Peskin M, Wiemann CM. Impact of a group prenatal program for pregnant adolescents on perceived partner support. Child Adolesc Social Work J. 2016;33(5):417-428

56. Brazelton TB. Ciba Clinics in Developmental Medicine, no. 50 Neonatal Behavioral Assessment Scale. Philadelphia, PA: JB Lippincott; 1973

57. Minnesota Early Learning Design. Meld for young dads curriculum: The other people in your life. Minneapolis, MN: by author; 1997

58. Rising SS. Centering pregnancy: An interdisciplinary model of empowerment. J Nurse Midwifery. 1998;43(1):46-54

59. Kabat-Zinn J. Full Catastrophe Living: Using the Wisdom of Your Body and
Mind to Face Stress, Pain, and IIIness. New York, NY: Delta; 1990

60. Pruett MK, Pruett K, Cowan CP, Cowan $P A$. Enhancing father involvement in low-income families: a couples group approach to preventive intervention. Child Dev. 2017;88(2):398-407

61. Raikes HH, Summers JA, Roggman LA. Father involvement in Early Head Start programs. Fathering. 2005;3(1):29-52

62. Bronte-Tinkew J, Horowitz A, Metz A. "What works" in fatherhood programs? Ten lessons from evidencebased practice. 2008. Available at: https://www.fatherhood.gov/sites/ default/files/files-for-pages/NRFC Practice Brief_What Works_508.pdf. Accessed March 15, 2018

63. Zanoni L, Warburton W, Bussey K, McMaugh A. Fathers as 'core business' in child welfare practice and research: an interdisciplinary review. Child Youth Serv Rev. 2013;35(7):1055-1070

64. National Fatherhood Initiative. Fatherfriendly check-up. 2016. Available at: https://www.fatherhood.org/ffcu Accessed March 15, 2018

65. Stahlschmidt MJ, Threlfall J, Seay KD, Lewis EM, Kohl PL. Recruiting fathers to parenting programs: advice from dads and fatherhood program providers. Child Youth Serv Rev. 2013;35(10):1734-1741

66. Dion R, Holcomb P, Zaveri $\mathrm{H}$, et al. Parents and children together: the complex needs of low-income men and how responsible fatherhood programs address them. 2018. Available at: https://www.acf.hhs.gov/sites/ default/files/opre/pact_fatherhood_ programs_022618_b508.pdf. Accessed March 15, 2018

67. Kotelchuck M, Lu M. Father's role in preconception health. Matern Child Health J. 2017;21(11):2025-2039

68. Walsh TB, Tolman RM, Singh V, Davis MM, Davis RN. Expectant fathers' presence at prenatal ultrasounds: an opportunity for engagement. Soc Work Res. 2017;41(3):181-185

69. Heckman JJ, Holland ML, Makino KK, Pinto R, Rosales-Rueda M. An Analysis of the Memphis Nurse-Family Partnership Program. Cambridge, MA: 
National Bureau of Economic Research; 2017

70. Guterman NB, Bellamy JL. The effects of the Dads Matter intervention on child maltreatment and co-parenting outcomes: preliminary findings. 2018; Washington, DC; January 12, 2018

71. Banman A, Harty J, Guterman NB, Bellamy JL, Morales-Mirque $S$. The effects of the Dads Matter intervention on father engagement and involvement: preliminary findings. 2018; Washington, DC; January 11, 2018

72. Guterman NB, Bellamy JL, Banman A. Promoting father involvement in early home visiting services for vulnerable families: findings from a pilot study of "Dads matter.". Child Abuse Negl. 2018;76:261-272

73. Barr R, Brito N, Zocca J, Reina S Rodriguez J, Shauffer C. The Baby Elmo Program: improving teen father-child interactions within juvenile justice facilities. Child Youth Serv Rev. 2011:33(9):1555-1562

74. Barr R, Morin M, Brito N, Richeda B, Rodriguez J, Shauffer C. Delivering services to incarcerated teen fathers: a pilot intervention to increase the quality of father-infant interactions during visitation. Psychol Serv. 2014;11(1):10-21

75. Israel D, Behrmann R, Wulfson S. Three Innovative Approaches to Serving Low-Income Fathers: The Building Bridges and Bonds Study. Washington, DC: Office of Planning, Research and Evaluation, Administration for Children and Families, U.S. Department of Health and Human Services; 2017

76. Harknett K, Manno MS, Balu R. . Building Bridges and Bonds: Study design report (OPRE Report 2017-27). Washington, DC: U.S. Department of Health and Human Services; 2017

77. Cowan PA, Cowan CP, Pruett MK, Pruett K, Wong JJ, LaRossa R. Promoting fathers' engagement with children: preventive interventions for lowincome families. J Marriage Fam. 2009;71(3):663-679
78. Cowan PA, Cowan CP, Pruett MK, Pruett $K$, Gillette P. Evaluating a couples group to enhance father involvement in low-income families using a benchmark comparison. Fam Relat 2014;63(3):356-370

79. Dorsey B. Conscious fathering: engaging expectant dads during the golden moment and equipping them to thrive. 2011. Available at: https://static1.squarespace.com/ static/56be46a6b6aa60dbb45e41a5/ t/584598c43e00be2980f29aba/ 1480956101306/ConsciousFathering. pdf. Accessed April 1, 2018

80. Raikes H, Boller K, vanKammen W, et al. Father involvement in Early Head Start programs: A practitioners study. 2002. Available at: http://ccfl.unl.edu/ projects_outreach/projects/previous/ pdf/Final_Father_Involvement_Report. pdf. Accessed April 1, 2018

81. Hayward-Everson RA, Honegger L, Glazebrook A, Rabeno S, Yim K. Predictors of father involvement in a sample of low-income men enrolled in a responsible fatherhood program [published online ahead of print March 20, 2018]. Soc Work Res. doi.org:10. 1093/swr/svy004

82. Raikes H, Bellotti J. Policies and programmatic efforts pertaining to fatherhood: commentary. Appl Dev Sci. 2007;11(4):271-272

83. Fagan J. Research on children's environmental programmatic efforts pertaining to fatherhood. Appl Dev Sci. 2007;11(4):260-265

84. Ledite R. An exploration of aspects of boundary ambiguity among young, unmarried fathers during the prenatal period. Fam Relat. 2007;56(2):162-174

85. Dallas CM. Interactions between adolescent fathers and health care professionals during pregnancy, labor, and early postpartum. J Obstet Gynecol Neonatal Nurs. 2009;38(3):290-299

86. Lee SJ, Hoffman G, Harris D. Community-Based Participatory Research (CBPR) needs assessment of parenting support programs for fathers. Child Youth Serv Rev. 2016;66:76-84

87. Lee SJ, Neugut TB, Rosenblum KL, Toman RM, Travis WJ, Walker MH. Sources of parenting support in early fatherhood: perspectives of United States Air Force members. Child Youth Serv Rev. 2013;35(5):908-915

88. Lee SJ, Yelick A, Brisebois K, Banks $\mathrm{KL}$. Low-income fathers' barriers to participation in family and parenting programs. J Fam Strengths. 2011;11(1):1-16

89. Teitler J0. Father involvement, child health and maternal health behavior. Child Youth Serv Rev. 2001;23(4-5):403-425

90. Garfield CF, Isacco A. Fathers and the well-child visit. Pediatrics. 2006;117(4) Available at: www.pediatrics.org/cgi/ content/full/117/4/e637

91. Dayton CJ, Buczkowski R, Muzik M, et al. Expectant fathers' beliefs and expectations about fathering as they prepare to parent a new infant. Soc Work Res. 2016;40(4):225-236

92. Davis RN, Davis MM, Freed GL, Clark SJ Fathers' depression related to positive and negative parenting behaviors with 1-year-old children. Pediatrics. 2011;127(4):612-618

93. Bronte-Tinkew J, Moore KA, Matthews G, Carrano J. Symptoms of major depression in a sample of fathers of infants sociodemographic correlates and links to father involvement. J Fam Issues. 2007;28(1):61-99

94. Lee SJ, Taylor CA, Bellamy JL. Paternal depression and risk for child neglect in father-involved families of young children. Child Abuse Negl. 2012;36(5):461-469

95. Committee on Hospital Care, American Academy of Pediatrics. Family-centered care and the pediatrician's role. Pediatrics. 2003;112(3, pt 1):691-697

96. Cox MJ, Paley B. Understanding families as systems. Curr Dir Psychol Sci. 2003;12(5):193-196

97. Rosenthal R. The "file drawer problem" and tolerance for null results. Psychol Bull. 1979;86(3):638-641 
Father-Inclusive Perinatal Parent Education Programs: A Systematic Review Joyce Y. Lee, Heather A. Knauer, Shawna J. Lee, Mark P. MacEachern and Craig F. Garfield

Pediatrics 2018;142;

DOI: 10.1542/peds.2018-0437 originally published online June 14, 2018;

\begin{tabular}{|c|c|}
\hline $\begin{array}{l}\text { Updated Information \& } \\
\text { Services }\end{array}$ & $\begin{array}{l}\text { including high resolution figures, can be found at: } \\
\text { http://pediatrics.aappublications.org/content/142/1/e20180437 }\end{array}$ \\
\hline References & $\begin{array}{l}\text { This article cites } 74 \text { articles, } 4 \text { of which you can access for free at: } \\
\text { http://pediatrics.aappublications.org/content/142/1/e20180437\#BIBL }\end{array}$ \\
\hline Subspecialty Collections & $\begin{array}{l}\text { This article, along with others on similar topics, appears in the } \\
\text { following collection(s): } \\
\text { Fetus/Newborn Infant } \\
\text { http://www.aappublications.org/cgi/collection/fetus:newborn_infant_ } \\
\text { sub }\end{array}$ \\
\hline Permissions \& Licensing & $\begin{array}{l}\text { Information about reproducing this article in parts (figures, tables) or } \\
\text { in its entirety can be found online at: } \\
\text { http://www.aappublications.org/site/misc/Permissions.xhtml }\end{array}$ \\
\hline Reprints & $\begin{array}{l}\text { Information about ordering reprints can be found online: } \\
\text { http://www.aappublications.org/site/misc/reprints.xhtml }\end{array}$ \\
\hline
\end{tabular}

\section{American Academy of Pediatrics}

DEDICATED TO THE HEALTH OF ALL CHILDREN ${ }^{\circledR}$ 


\section{PED I ATR I C S}

OFFICIAL JOURNAL OF THE AMERICAN ACADEMY OF PEDIATRICS

Father-Inclusive Perinatal Parent Education Programs: A Systematic Review Joyce Y. Lee, Heather A. Knauer, Shawna J. Lee, Mark P. MacEachern and Craig F. Garfield

Pediatrics 2018;142;

DOI: 10.1542/peds.2018-0437 originally published online June 14, 2018;

The online version of this article, along with updated information and services, is located on the World Wide Web at:

http://pediatrics.aappublications.org/content/142/1/e20180437

Data Supplement at:

http://pediatrics.aappublications.org/content/suppl/2018/06/13/peds.2018-0437.DCSupplemental

Pediatrics is the official journal of the American Academy of Pediatrics. A monthly publication, it has been published continuously since 1948. Pediatrics is owned, published, and trademarked by the American Academy of Pediatrics, 345 Park Avenue, Itasca, Illinois, 60143. Copyright (C) 2018 by the American Academy of Pediatrics. All rights reserved. Print ISSN: 1073-0397.

\section{American Academy of Pediatrics}

DEDICATED TO THE HEALTH OF ALL CHILDREN ${ }^{\circledR}$ 